\title{
CORPOS SILENCIADOS: OS DADOS DA VIOLÊNCIA SEXUAL CONTRA MULHERES NO RIO DE JANEIRO
}

SILENCED BODIES: DATA ON SEXUAL VIOLENCE AGAINST WOMEN IN RIO DE JANEIRO

\author{
Carolina da Silva Santos ${ }^{\text {A }}$ \\ (i) Gabriel Siqueira Corrêa ${ }^{\text {B }}$ \\ Ana Beatriz da Silva Anacleto ${ }^{\mathrm{C}}$ \\ ${ }^{\text {A }}$ Universidade do Estado do Rio de Janeiro (Uerj), São Gonçalo, RJ, Brasil \\ ${ }^{\text {B }}$ Universidade do Estado do Rio de Janeiro (Uerj), São Gonçalo, RJ, Brasil \\ ${ }^{\mathrm{C}}$ Universidade do Estado do Rio de Janeiro (Uerj), São Gonçalo, RJ, Brasil
}

Recebido em: 23 abr. 2021 | Aceito em:29 ag. 2021 Correspondência:Carolina da Silva Santos (carolinasantos90@gmail.com)

\section{Resumo}

No presente artigo, objetiva-se expor os dados de violência sexual no estado do Rio de Janeiro sob a perspectiva feminista. Para tanto, a metodologia utilizada baseia-se no levantamento e na análise de dados elaborados pelo Instituto de Segurança Pública (ISP), bem como nos documentos do Dossiê Mulher - entre os anos de 2006 e 2018. Como resultados preliminares, identificaram-se que o maior número de denúncias em relação à violência sexual, registradas na Delegacia Especializada de Atendimento à Mulher (DEAM), é contra crianças e adolescentes do gênero feminino. Ademais, que é no ambiente doméstico que ocorrem o maior número de casos cometidos por pessoas próximas ao convívio das vítimas.

Palavras-chave: corpo feminino; violências; violência sexual.

\begin{abstract}
In this article, the objective is to expose the data on sexual violence in the state of Rio de Janeiro from a feminist perspective. For this purpose, the methodology used is based on the survey and analysis of data prepared by the Public Security Institute (ISP), as well as on the documents of the Women's Dossier - between the years 2006 and 2018. As preliminary results, it was identified that the largest number of complaints regarding sexual violence, registered at the Specialized Police Service for Women (DEAM), is against female children and adolescents. Furthermore, it is in the domestic environment that the largest number of cases committed by people close to the victims' lives occur.
\end{abstract}

Keywords: feminine body; violence; sexual violence. 


\section{Introdução}

A discussão sobre a violência sexual cometida contra mulheres, crianças e adolescentes, revela dados alarmantes no Brasil e expõe uma problemática a ser analisada e enfrentada pela sociedade. Desse modo, o estudo do tema, em questão, contribui para a visibilidade e problematização do fenômeno na escala local do estado do Rio de Janeiro; possibilitando refletir sobre a necessidade de políticas de prevenção e atendimento. Este trabalho foi organizado em três momentos específicos: no primeiro, realiza-se breve conceituação do corpo em sua escala de violência; no segundo momento, aborda-se o movimento feminista e sua participação no combate à violência. Por fim, na terceira parte, serão expostos os dados sobre violência sexual, na busca de uma reflexão sobre as políticas públicas.

Desta forma, como princípio metodológico, será realizada uma análise crítica dos dados que estão reunidos em 14 volumes do Dossiê Mulher, publicados pelo Instituto de Segurança Pública - ISP. A forma do levantamento foi feita com acesso a esses documentos que estão disponibilizados no site do ISP. Cada ano apresenta uma particularidade, contudo o foco será nos dados que são importantes para esse artigo. Isto posto, é feito um breve levantamento do quantitativo de registros de denúncias em casos que se enquadram na tipologia de violência sexual, com um comparativo temporal que tem um recorte entre os anos de 2004 a 2018.Assim, este artigo apresenta o diálogo entre os conceitos de violência, violência de gênero e violência patriarcal.

\section{O corpo feminino e a violência cotidiana}

$\mathrm{O}$ corpo ${ }^{\mathrm{i}}$ feminino vivencia um histórico de múltiplas violências, individuais e coletivas, cotidianamente. É socializado em padrões de gênero na sua vivência cultural, emocional e política - sendo violentado, domesticado e docilizado (FEDERICI, 2017). Este processo atravessa ações exercidas pelas pessoas, grupos, instituições, poder público, entre outros agentes que atuam com diferentes mediações e níveis de alcance. Isso acontece na forma de agir, falar, se comportar, onde andar, funções na família, na casa, na cama, comportamento com as filhas e filhos, amigas e amigos, como, também, no trabalho.

Foucault (1987) aborda em seu livro Vigiar e Punir sobre os aparelhos que docilizam e disciplinam os corpos. O autor expõe como este modelo de controle introduz, no 
cotidiano,funções, obrigações e ações que seguem regras normatizadoras. Tem-se, assim, um padrão social feito para manter um arquétipo de família patriarcal, dentro de um sistema econômico.

Em sua materialidade, o corpo vivencia múltiplas violências que são investidas sobre si, por sua representação social. Com isso, existem diversas características que, como Louro (2004) apresenta, marcam as opressões e violências que vão ser enfrentadas pelo mesmo corpo, na sociedade, e que são unicamente baseadas em padrões culturais que definem papéis de subalternização de diferentes corpos:

Hoje, como antes, a determinação dos lugares sociais ou das posições dos sujeitos no interior de um grupo é referida a seus corpos. Ao longo dos tempos, os sujeitos vêm sendo indiciados, classificados, ordenados, hierarquizados e definidos pela aparência de seus corpos; a partir dos padrões e referências, das normas, valores e ideais da cultura. Então, os corpos são o que são na cultura. A cor da pele ou dos cabelos; o formato dos olhos, do nariz ou da boca; a presença da vagina ou do pênis; o tamanho das mãos, a redondeza das ancas e dos seios são sempre, significados culturalmente e é assim que se tornam (ou não) marcas de raça, de gênero, de etnia, até mesmo de classe e de nacionalidade (LOURO, 2004, p.75)

Com isso, percebe-se que existe um modelo de vivência na sociedade que define identidades e papéis de gênero, os quais são reforçados em diferentes espaços como na escola, nas tramas políticas que regem a vida cotidiana, na organização da religiosidade predominante, entre outros. O que se recorda de Simone de Beauvoir (1967, p.9) é que: "Ninguém nasce mulher: torna-se mulher. Nenhum destino biológico, psíquico, econômico define a forma que a fêmea humana assume no seio da sociedade; É o conjunto da civilização que elabora esse produto intermediário. [...]"

Destaca-se, portanto, que os corpos de mulheres são vistos de formas diferentes e, com isso, as violências que sofrem mudam, segundo as características de raça, classe, idade e sexualidade, como exposto, por bell hooks ${ }^{\text {ii }}$ (2019). Ainda se inserem a este campo os diferentes espaços que estes corpos frequentam. Então, as mulheres ficam cada vez mais expostas às violências cotidianas que estão envoltas por padrões sociais e culturais.

Em uma pesquisa realizada por Campos, Silva \& Silva(2019), com 11 mulheres que sofreram violência sexual, identificou-se que o corpo era relatado diversas vezes como espaço que fora invadido. O agressor-homem impôs seu poder e sua força, adentrando no espaço privado da mulher. Além disso, verificou-se que, é no espaço do corpo que, são construídas e reafirmadas a sua autonomia em sua potencialidade na escala de resistência. No caso da violência sexual, este cruzamento é contrário à vontade do agente desse espaço - por isso é violento. "Violência de gênero, inclusive em suas modalidades familiar e doméstica, não 
ocorre aleatoriamente, mas deriva de uma organização social de gênero, que privilegia o masculino" (SAFFIOTI, 2015, p. 85).

A violência doméstica é uma violência sexista, além de ser uma violência patriarcal, que estão envoltas nas relações de poder que, neste caso, reforçam o poder de homens contra mulheres, como aponta bell hooks (2019):

A violência patriarcal em casa é baseada na crença de que é aceitável que um indivíduo mais poderoso controle outros por meio de várias formas de força coercitiva. Essa definição entendida de violência doméstica inclui a violência de homens contra mulheres, a violência em relacionamentos entre pessoas do mesmo sexo e a violência de adultos contra crianças. O termo "violência patriarcal" é útil porque, mais comum, ele constantemente lembra o ouvinte que violência no lar está ligada ao sexismo e ao pensamento sexista, à dominação masculina (hooks, 2019, pp. 95-96).

Assim, o termo violência patriarcal é importante, pois está associado a um processo histórico que "dá" ao homem a permissão de controle e poder sobre o corpo da mulher. As relações de poder são o fio condutor de tudo que é exposto aqui. Foucault $(1995,2011)$ e Raffestin (1993) sinalizam que relações assimétricas de poder têm a capacidade de influenciar, manipular e estabelecer normas de comportamento de indivíduos ou coletivos. Para Weber (1999), dominação é uma forma de encontrar obediência. Já para Saffioti (2015):

[...]compreende-se que o processo de dominação só passa a se estabelecer numa relação social. Desta forma, há o(s) dominador(es) e o(s) dominado(s). O(s) primeiro(s) não elimina(m) o(s) segundo(s), nem pode ser este seu intento. Para continuar dominando, deve(m) preservar seu(s) subordinado(s). Em outros termos, dominação presume subordinação. Portanto, está dada a presença, no mínimo, dois sujeitos. E sujeito atua sempre, ainda que situado no polo de dominado. Se o esquema de dominação patriarcal põe o domínio, a capacidade legitimada de comandar, nas mãos do patriarca, deixa livre aos seus subordinados, homens e mulheres, especialmente estas últimas, a iniciativa de agir, cooperando neste processo, mas também solapando suas bases. Eis aí a contradição que perpassa as relações homem-mulher na ordem patriarcal de gênero. Aliás o conceito de dominação, em Weber, é distinto do conceito de poder. Enquanto a primeira conta com a aquiescência dos dominados, o poder dispensa-a, podendo mesmo ser exercido contra vontade dos subordinados. (SAFFIOTI, 2015, p. 125-126)

A violência de gênero que as mulheres sofrem é uma estratégia hegemônica organizada socialmente como uma violência "invisível", naturalizada nas relações sociais.Explicada por Bourdieu (1989) é definida como violência simbólica. Sobre a dominação masculina, Bourdieu (2002), também, debate a partir do processo de naturalização das estruturas cognitivas de dominação. Para o autor, a ordem masculina se dá a partir de operações e rituais de exclusão das mulheres - e do feminino. Com isso, se vê caracterizada a violência contra a mulher. Gonzales (2011) aponta que mulheres não brancas, como é o caso de negras e indígenas, sofrem de forma potencializada a violência sobre seus corpos. 
O espaço de violência doméstica compõe um ambiente de abuso. Mulheres, mães, crianças, jovens e adolescentes vítimas de violência, vivem essas situações muitas vezes dentro de suas casas. Mas não apenas nesse espaço, pois a violência pode ocorrer no espaço público ou privado. A violência doméstica não abarca apenas a violência contra a mulher, mas sim contra todos e todas que convivem nessa esfera, incluindo crianças, adolescentes e idosos. Tal violêncianão precisa acontecer no âmbito da unidade doméstica; ela pode ocorrer no âmbito da família (seja onde for) e em meio a "qualquer relação íntima de afeto". O que define a violência doméstica não é um espaço específico, mas sim as formas de relações sociais específicas preexistentes entre o agressor e a pessoa violentada. Issonão "desespacializa" a violência doméstica contra a mulher, mas a complexifica.

Afinal, podendo acontecer em diferentes espaços (e considerando que o espaço constitui e condiciona os comportamentos), pode-se, facilmente, afirmar que as manifestações empíricas das formas de violência doméstica contra a mulher também variam de espaço para espaço: uma violência física que ocorre dentro de casa pode coexistir com a violência moral e psicológica no restaurante, bar, mercado, rua e, pode coexistir, também, com a violência patrimonial no consultório médico ou no espaço de estudo. Essas variações também dizem respeito às formas como agressor e vítima se posicionam e são posicionados socialmente nesses distintos espaços.

É importante reconhecer isso para não simplificar a violência doméstica, restringindoa àquelas ações que ocorrem no espaço da unidade domiciliar. Embora a identificação dessa unidade espacial indique uma escala geográfica específica (reconhecida e apontada inclusive pela lei), ao identificar a complexidade dessas formas de violência torna-se ainda mais evidente que este recorte do espaço está estreitamente interligado com outros espaços por meio da relação de violência estabelecida entre agressor e vítima. Assim, fica nítido que a violência doméstica contra a mulher, como prática social, escalariza a experiência tanto da vítima quanto do agressor: a casa torna-se um espaço contíguo de violações cuja existência depende de outros espaços.

Por muito tempo, o termo violência doméstica tem sido usado como um termo "suave", que sugere emergir em um contexto íntimo que é privado e de alguma maneira menos ameaçador, menos brutal, do que a violência fora do lar. Isso não procede, já que mais mulheres são espancadas e assassinadas em casa do que fora dela. (hooks, 2019, p.96)

Uma vez que socialmente a mulher é considerada como responsável pela família, todo o peso desses problemas recai sobre ela de maneira redobrada. A família, no interior da qual 
se esperaria haver relações de proteção e confiança, se torna muitas vezes um dos ambientes mais inseguros e mais violentos pelos mais diferentes tipos de violência (psicológica, física, emocional, financeira, dentre outras). E é nesse espaço que uma criança se desenvolve, onde recebe ou deveria receber orientação, cuidados e proteção.

\begin{abstract}
A mãe, assim como sua filha/o, precisa de ajuda para sair do estado de choque que a violência causou, mas esse pode ser um processo longo e doloroso. Isto porque, até tomarem uma postura ativa diante da situação em que vivem, as mães experimentam vários tipos de sentimentos, tais como: negação, medo, ansiedade, culpa e resistência, principalmente aquelas que também sofreram o mesmo tipo de violência e, em especial, a sexual. Assim, pelas consequências que esses tipos de sentimentos podem causar, o apoio às mães se torna de extrema importância e necessidade no processo do tratamento psicoterapêutico continuado às vítimas de violência e abuso sexual. (CERQUEIRA, et al., 2015,p. 116)
\end{abstract}

A expressiva violência, dentro do lar, tem influência direta na construção do espaço privado relegado às mulheres e sua subordinação em relação ao homem. Dessa forma, embora sejam múltiplos os fatores que influenciam a violência doméstica, a construção de uma sociedade patriarcal é um dos pilares que sustenta a aceitação e naturalização desse problema. Assegurar a essas mulheres, vítimas de violência doméstica proteção e apoio, é papel importante dos governos federais, estaduais e municipais com adesão de toda sociedade. É preciso que as mulheres, filhas e filhos tenham direito de denunciar e se libertar desses espaços de violência.

A violência física, em suas diversas manifestações, pode estar entrelaçada à violência sexual, psicológica, simbólica, verbal, negligência, entre outras, e envolve diversos agentes. Crianças e adolescentes do sexo masculino são os que mais sofrem violência física; mulheres e crianças do sexo feminino as que mais sofrem violência intrafamiliar no âmbito doméstico. Os índices (UNICEF/IBGE, 2001) englobam mulheres adultas e crianças do sexo feminino, e apontam que quase dois terços $65,8 \%$ - das vítimas de agressão intrafamiliar são mulheres. Em seu recorte de gênero, o abuso físico é mais praticado pelas mães e atinge mais os meninos. Diz o relatório da OMS (id.,ibid) que isto provavelmente ocorre porque as mães têm mais contato com a criança, como cuidadoras, e tendem, através da aplicação da força física, a lhes estimular o comportamento agressivo que a sociedade espera dos meninos. (BARROS, 2005, p. 53-54).

No processo educativo de uma criança, é comum,na sociedade, o uso da violência como modo de punição. Dentro de uma estrutura familiar as hierarquias são muitos fortes e demarcam quem controla e quem detém o poder. $\mathrm{O}$ homem possui esse controle, apoiado pela sociedade patriarcal essencialmente machista, que o dá o direito não apenas sobre a mulher, mas também sobre sua família.

A violência doméstica como um fenômeno complexo integra uma vasta gama de componentes relacionais que são pautados em vínculos subjetivos construídos 
socioculturalmente, por meio dos diversos modos de comunicação específicos. As relações travadas nestes contextos refletem a situação de desigualdade e a assimetria que conformam as relações de poder estabelecidas. O espaço privado, isto é, a esfera doméstica, mesmo que seus contornos não sejam monoliticamente definidos e a sua abrangência abarque sentidos além dos territoriais - incluindo-se questões representativas, simbólicas, subjetivas e objetivas -, constitui uma importante tessitura implicada a outras construções societárias. Esta estruturação define o habitus incorporado e o exercício de poder estabelecido, muitas das vezes, com a supressão de autonomia e extinção dos limites de alteridade de outros membros. (BARROS, 2005, p. 39)

Portanto, não existe libertação sexista sem que se tenham esses debates alinhados. Esse elemento ressalta a importância de se compreender que homens e mulheres estão sendo, de formas diferenciadas, socializados nesse sistema opressor, indicando seus papéis na sociedade.

\section{Feminismo e os corpos em luta}

A luta pelo território e espaço feminino é um processo que acontece àdécadas, resultado de resistência e militância. Sarti (2004) afirma que as ondas internacionais tiveram uma grande influência na militância brasileira, a partir da década de 70 do século XX, unindose a diversos outros grupos políticos na luta por direitos, modificando-se e tendo diversas divergências no contexto nacional nos períodos amargos da ditadura e da democratização a partir dos anos 1980 e 1990.

A autora explica que, nesse momento histórico de levante, a participação política das mulheres ecoava sons de resistência nas ruas, marcava pontos e delimitava novos territórios e cenários de luta por direitos e contra as relações de poder estruturais, sociais e culturais. Seja com o apoio internacional, que auxiliava na pressão feita sobre o Estado pela criação de políticas públicas, bem como com vínculos em organizações não governamentais feministas. As lutas resultaram em grandes conquistas; uma delas foi em 1985, quando as primeiras delegacias para as mulheres foram criadas. Existe, portanto, um problema social que não deve ser mais invisibilizado, mas sim denunciado.

As pautas feministas, cada vez mais fortes, abarcavam temas diversos e importantes no cenário nacional e internacional. Os direitos reprodutivos e a violência contra a mulher são dois, dos principais exemplos. A esfera política, após a ditadura, fica mais acessível aos movimentos sociais e movimentos feministas - diante de uma constituição democrática e inclusiva.

Percebemos, assim, que após a ditadura o feminismo foi se adentrando na esfera política e conquistando aos poucos seu espaço em órgãos públicos importantes. Através da chamada Carta das Mulheres à Assembleia Constituinte, as demandas 
feministas foram apresentadas à sociedade civil, introduzindo as mulheres dentro do Congresso Nacional, para suas respectivas reivindicações de direitos mais igualitários - neste período se reconheceu o movimento feminista como o movimento da sociedade civil que mais conquistou vitórias (OLIVEIRA e CASSAB, 2014. p.5).

Nesse contexto, a Organização das Nações Unidas (ONU), em 1975, declara aquele ano como o Ano Internacional das Mulheres e contribui para o fortalecimento dos movimentos feministas ao reconhecer que a situação da mulher é um problema social. A expansão dos movimentos de mulheres que, em suas articulações vindas de camadas médias se vincularam com outras frentes populares, começa a se caracterizar como movimentos interclasse e a expandir suas redes de atuação (SARTI, 2004; FEDERICI, 2019).

Silva (2000), por sua vez, apresenta que as demandas das mulheres brasileiras, nesse período do ativismo feminino, vinham contra os altos custos de vida, a favor da inserção no mercado de trabalho (consequentemente atrelada a políticas públicas específicas, como a construção e manutenção de creches), além das questões salariais. Essas pautas as faziam caminhar lentamente por um espaço político.

Atualmente, as reivindicações dos movimentos feministas abarcam também o combate à violência no espaço doméstico (tanto física quanto psicológica), ao abuso e exploração sexual e à condição precária vivenciada ainda por muitas mulheres em países conservadores. Todavia, é importante assinalar que muitos aspectos da luta feminista inicial continuam, como a luta pelo direito ao aborto, ainda ilegal em muitos lugares (como é na realidade brasileira), e o salário que, em muitos países, ainda é inferior ao dos homens. (SEPULVEDA, 2012, p. 200)

O resgate, de forma resumida, dessa trajetória do movimento feminista é para que seja possível compreender o contexto em que se configuram diversos processos que não constituem, de forma alguma, uma linearidade ou um roteiro. São décadas de resistência, pautas que se constroem e se organizam ao longo dos anos, grupos que se unem e se desfazem e se reorganizam. Os movimentos são constituídos por pessoas plurais que trazem consigo experiências diversas e que estão em constante transformação.

É importante perceber que todos esses resultados são provenientes de luta e organização, pois as conquistas são construídas por meio de muita pressão social organizada. Assim, se percebe a influência que os movimentos sociais —nesse caso o movimento de mulheres- conseguem ao se unir.

\section{A violência sexual e corpos marcados}

Como pôde-se perceber, com as reflexões expostas acima, a violência é um fenômeno que afeta toda a sociedade. Ao falar sobre a violência sexual é possível identificá-la como um 
problema de saúde pública. Face ao exposto, para compreender a definição do conceito na legislação brasileira, a violência sexual é:

[...]todo ato ou jogo sexual com intenção de estimular sexualmente a criança ou o adolescente, visando utilizá-lo para obter satisfação sexual, em que os autores da violência estão em estágio de desenvolvimento psicossexual mais adiantado que a criança ou adolescente. Abrange relações homo ou heterossexuais. Pode ocorrer em uma variedade de situações como: estupro, incesto, assédio sexual, exploração sexual, pornografia, pedofilia, manipulação de genitália, mamas e ânus, até o ato sexual com penetração, imposição de intimidades, exibicionismo, jogos sexuais e práticas eróticas não consentidas e impostas e "voyeurismo" (obtenção de prazer sexual por meio da observação) (BRASIL, 2004, s.p.).

Sendo, ainda, tipificada como crime, exposta na Lei 11.340/2006:

Violência sexual: presenciar, manter ou obrigar a participar de relação sexual não desejada, mediante intimidação, ameaça, coação ou uso da força, que induza a mulher a comercializar ou utilizar, de qualquer modo, a sua sexualidade (Lei $\mathrm{N}^{\circ}$ $11.340 / 2006)$.

Um documento que ajuda a trabalhar quantitativamente com as práticas de violência sexual é o Dossiê Mulheriii. Esse é elaborado anualmente pelo Instituto de Segurança Pública ${ }^{\text {iv }}$ - ISPe, ao longo dos anos, teve contribuições de outras instituições, órgãos e ONGs no auxílio da sintetização, apuração e diagnóstico dos dados. Referência em todo o país neste tipo de trabalho, realiza um papel importante na visualização de dados ${ }^{v}$ da violência contra mulher em todo Estado do Rio de Janeiro ao produzir materiais temáticos anualmente.

A tabela 1 é uma síntese de todos os dados referentes ao Estado do Rio de Janeiro, com as categorias usadas em cada ano pelos dossiês referentes à violência sexual. Esses são os dados que serão analisados de forma mais efetiva. Uma observação é que em cada dossiê, os levantamentos foram feitos com uma organização diferente, alterando a tipologia apresentada. O levantamento se inicia pelo Instituto de Segurança Pública - ISP em 2005, e começa a reunir dados oficiais de violência contra a mulher em todo estado. Assim, o Dossiê Mulher começa a ser publicado periodicamente.

Tabela 1 - Violência Sexual - Dados do Estado do Rio de Janeiro 


\begin{tabular}{|c|c|c|c|c|c|c|c|c|c|c|c|c|c|c|c|c|c|}
\hline \multicolumn{18}{|c|}{ Tabela 1 - Violência Sexual - Dados do Estado do Rio de Janeiro } \\
\hline & Delitos & 20052 & 2006 & 2007 & 20082 & 2009 & 2010 & 2011 & 2012 & 2013 & 2014 & 2015 & 2016 & 2017 & 2018 & Total de delitos & Total das violências \\
\hline \multirow{7}{*}{ Violência Sexual } & Atentado Violento ao Pudor & $-\cdot \cdot$ & 1272 & 1306 & 1679 & \multirow{2}{*}{4120} & $\cdot$ & $\cdot$ & $\cdot$ & $\cdot$ & - & $\cdot$ & - & - & $\cdot$ & \multirow{2}{*}{56816} & \multirow{7}{*}{63026} \\
\hline & Estupro & $\cdot$ & 1278 & 1376 & 3843 & & 4589 & 4871 & 6029 & 4871 & 4725 & 4128 & 4013 & 4173 & 4543 & & \\
\hline & Tentativa de estupro & - & $\cdot$ & $\cdot$ & 410 & 408 & 351 & 403 & 387 & 556 & 586 & 484 & 387 & 356 & 308 & 3467 & \\
\hline & Assédio sexual & - & - & - & - & $\cdot$ & - & & & & 120 & 134 & 126 & 125 & 150 & 535 & \\
\hline & Importunação ofensia ao pudor & - & - & - & - & - & - & & & & 695 & 610 & 588 & 595 & 638 & 1821 & \\
\hline & Ofensiva ao pudor & $=$ & - & - & - & - & - & & & & & & & & & & \\
\hline & Ato obsceno & 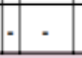 & - & $\cdot$ & \begin{tabular}{|l|l}
$\cdot$ \\
\end{tabular} & $\cdot$ & $\cdot$ & & & & 310 & 283 & 270 & 194 & 193 & 387 & \\
\hline \multicolumn{18}{|c|}{ Elaboração da/0 autora/o (Fonte ISP) } \\
\hline
\end{tabular}

Fonte: Dados da Pesquisa

Algumas considerações acerca desses dados são importantes, para entender como a legislação altera a percepção das formas de violência sexual. No documento publicado em 2006, o que chama atenção é que os estupros foram relacionados apenas aos que tiveram as mulheres como vítimas e com penetração vaginal, demonstrando um maior índice por agressores desconhecidos. Quando se expõe essa informação da legislação,a percepção sobre os dados muda, pois até esse momento o estupro era caracterizado em uma categoria limitada, bastante específica.

Assim, retiram-se outras formas de violência sexual de serem registradas como estupro, se não estiverem conforme tipificação da lei. Cabe assinalar que esta legislação não é tão antiga, e que sua mudança é bastante recente - o que preocupa ao pensar como esses crimes eram tratados anteriormente. O que muda, no entanto, é a forma de como é feito o registro e o tratamento da denúncia.

O estupro e o atentado violento ao pudor (AVP) estão caracterizados como crimes contra a liberdade sexual no capítulo I do título VI do Código Penal, que trata de crimes contra os costumes. Segundo a definição do Código Penal, o estupro ocorre quando existe o constrangimento da mulher à conjunção carnal, mediante violência ou grave ameaça (art.123), e o atentado violento ao pudor, quando há o constrangimento de alguém, mediante violência ou grave ameaça, a praticar ou permitir que com ele se pratique ato libidinoso diverso da conjunção carnal (art.214). Para ambos os crimes, a pena é de reclusão de 6 (seis) a 10 (dez) anos. (DOSSIÊ MULHER, 2006, p.7)

Mas asautoras e os autores chamam a atenção para essa primeira problemática, sabendo que homens e meninos sofrem também esse tipo de violência e eram enquadrados apenas como atentado violento ao pudor. Assim, como qualquer ato sexual que não fosse vaginal, tais como: sexo anal, sexo oral, além de feitos pelo toque das mãos, entre outras formas. Nesse momento já se percebe uma dificuldade na categorização dos dados, bem como na impercepção de alguns desses. 
Apenas no quarto relatório publicado em 2009, com ano base 2008, além da Lei 11340/06, é apresentada a implementação da Lei $\mathrm{n}^{\circ} 12.015 / 2009^{\mathrm{vi}}$, que tem alterações importantes de como é tipificado o delito de estupro, saindo, portanto, do rol de Crimes contra os Costumes para Crimes contra a Dignidade Sexual. Entre as mudanças nessa legislação, nota-se que homens e mulheres estão ancorados nessa, o que não acontecia anteriormente assim como o crime de estupro de vulnerável, que é tipificado e incorporado.

Ao longo dos documentos, as categorizações passam a incorporar essas legislações, contribuindo para melhor identificação dos dados. Essa adaptação também está relacionada à preparação e à formação dos agentes policiais que direcionam as denúncias, e precisam de tempo para entenderem e aplicarem as novas leis. Assim, conforme os dados foram sendo coletados e expostos, os documentos passaram a categorizar, com maior eficácia, identificando as práticas e formas da violência. Esse processo de coleta e categorização diz respeito a aspectos metodológicos e a aplicabilidade da lei, além da dimensão comportamental e subjetivo dos agentes policias.

No Dossiê Mulher 2011 já se percebe uma mudança significativa de como é, abordado, o crime de estupro. Usa-se apenas o título do crime de estupro e não utiliza mais o de atentado violento ao pudor. A mudança ocorre pela nova tipificação do crime pela Lei $\mathrm{n}^{\mathrm{o}} .12 .015 / 09$, de 07 de agosto de 2009 .

O crescimento no total de mulheres vítimas, de tentativa de estupro, se destaca. Vale considerar que, com a criação da Lei $\mathrm{n}^{\circ}$ 12.015/09, esperava-se a redução de registros de tentativa de estupro e não o inverso. Porém, é de se considerar sendo tão recente essa mudança. Ademais, esse é um dos crimes que gera diversos debates na sociedade em que, em sua maioria, responsabilizam e questionam a vítima.Assim, o aumento dos números pode representar a maior confiança nas instituições de proteção à mulher;o que demonstra certo amadurecimento no debate.

O Dossiê Mulher 2018 (ano base 2017) inclui, nesta edição, o ato obsceno, um tipo de crime de violência sexual que ocorre muitas vezes em meios de transporte público. Esse traz debate da importância da implementação de sistemas, que possam dialogar nacionalmente com dados organizados que consiga mapear os casos de violência e sintetizar informações que são cruciais no combate à violência. As parcerias são necessárias como, por exemplo, o trabalho feito pelas ONG's na luta contra violência.Porém, é necessário mecanismo do estado para que possa organizar os dados,além de auxiliar no combate e elaboração de políticas públicas. 
O estupro está no topo das denúncias e, a maioria das vítimas, são crianças e adolescentes. Cabe destacar que o Estatuto da Criança e Adolescente (ECA) aponta que crianças são aquelas que têm até 12 anos incompletos e adolescentes são pessoas entre 12 e 18 anos incompletos. Esse grupo possui uma particularidade, um grau de baixa compreensão e identificação do que está passando, tendo em vista que, os acusados, em sua maioria, são pessoas que deveriam cuidar e protege-las.

Os relatórios apontam que, usualmente, os agressores são parentes, conhecidos ou pessoas com envolvimento amoroso ou afetivo com a vítima. Além do levantamento do perfil do acusado, o documento também traz o perfil de vítimas por tipo de violência. No caso da violência sexual, as vítimas têm entre 0 à 17 anos e a maioria dos acusados tem algum tipo de relação com elas. As meninas entre 14 e 17 anos também estão no topo das violências físicas. Dessa forma, os casos que envolvem mulheres são mais recorrentes.

Entende-se que um fato problemático, no caso desse grupo que sofre estupro e tentativa de estupro, é a relação com o agressor, pois ela pode ser diária (pais, irmãos, tios, primos e pessoas próximas). Além disso, muitas das vítimas são jovens, o que muitas vezes resulta em menor autonomia para se mover pela cidade. Isso não anula o fato de as mulheres maiores de 18 anos sofrerem violências. Ainda, é importante levar em conta a subnotificação nesses casos, principalmente com jovens e crianças que têm em suas casas os agressores. Muitas dessas vítimas necessitam que uma outra pessoa tome parte ou denuncie. O perigo está, também, no fato de as agressões serem recorrentes por esse convívio. Muitas crianças só identificam ${ }^{\text {vii }}$ ou expõem que passaram por algum tipo de violência sexual após a vida adulta.

O medo e silêncio, das vítimas, acabam por auxiliar na subnotificação dos casos de estupro. Torna-se, portanto, um agravante, o agressor estar no meio de convívio de suas vítimas, pois ocorre uma maior probabilidade de recorrência da violência. Isso demonstra que a casa e a relação de proximidade que se reproduz nesse espaço, em muitos casos, não são condições favoráveis ao acolhimento e segurança. Ao contrário, são espacialidades que favorecem a violência e o silenciamento, de modo que um tipo de violência acaba se associando a outros. Essas múltiplas formas de violência não aparecem simultâneas nos dados, pois há uma organização em categorias nos registros, que formata as formas de violência em "caixas". Por exemplo: uma pessoa que sofre violência sexual tem o registro feito nesse tipo de crime. Esse modo de enquadramento ignora que esse tipo de violência é perpassado por outras, como a violência física e violência psicológica. 
Estes corpos sofrem mais de um tipo de violência, mesmo que os crimes sejam registrados dentro de um tipo de delito. Isso sem levar em consideração as feridas psicológicas em todas as formas de violência, que pela sua subjetividade e individualidade, não são expressas nos dados.

Mesmo com uma legislação de referência no mundo, os dados ainda são preocupantes e a necessidade de combate e enfrentamento é visível - tendo como base os documentos analisados. É importante sinalizar que a Lei Maria da Penha auxiliou na visibilização da violência sexual dos estupros maritais que, anteriormente, não eram vistos assim. Pois, entra em um conflito social com a ideia de que o sexo dentro do casamento é dever e, portanto, não ocorre estupro. Essa leitura coloca como obrigação, da mulher, satisfazer as necessidades de seu marido. A lei dá visibilidade e chama atenção para que qualquer relação sem consentimento fora, ou dentro, de um relacionamento amoroso é crime.

\footnotetext{
Quando observamos os índices de violência, a sexual é a menos frequente dentre os demais tipos, sobretudo entre parceiros íntimos. Essa invisibilidade da violência sexual se explica pelo constrangimento que as mulheres apresentam em denunciar, por ocorrer no interior das relações por parceiro íntimo e estar vinculada a questões de poder. (COELHO, SILVA, LINDNER, 2014, p.24)
}

Entre os dados alarmantes, nos números do Estado do Rio de Janeiro, a residência teve mais de $70 \%$ dos casos de estupro de mulheres, o que demonstra que, como no âmbito privado, a vulnerabilidade é maior na violência sexual do que nos espaços públicos. Outra informação que se repete, à medida que em muitas formas de violência perpassam por essas condições, é que os agressores são pessoas que têm algum tipo de relação com a vítima como: pais, padrastos ou parentes, companheiros ou ex-companheiros.

Com a mudança da lei do estupro, ficou uma linha tênue entre tentativa e consumação do estupro, estando-a, na mão do inquérito e do policial, encaminhar de acordo com o que é apurado da vítima - o que pode, muitas vezes, mudar os rumos dos dados.

Outra informação que chama atenção ao analisar os dados é que, no caso do crime de tentativa de estupro, os acusados nem sempre têm relação com a vítima, diferente do de estupro, o que pode se ver pelo altíssimo número de vítimas de estupro no ambiente familiar.

Vale destacar que, ao reunir todos os dados dos documentos, de acordo com as tipificações da Lei 11.340/06, aparecem com maior frequência as seguintes formas de violência: Física, Sexual, Moral, Patrimonial e Psicológica. Destaca-se, ainda, que a mulher é a vítima na maioria das ocorrências. No que diz respeito à dimensão étnico-racial, as mulheres 
negras e pardas são as mais violentadas, estando sempre no topo dos dados em casos de agressões mais graves e mortais, em todo o estado.

Essa informação demonstra a importância do debate da interseccionalidade de gênero e raça, quando se debate a violência letal sobre a mulher negra, como abordado por Davis (2016, 2017) e bell hooks (2016). Portanto, vale ressaltar que o problema da violência de gênero também pode ser associado ao debate sobre o racismo. Isso é observado pelo perfil analisado e nos dados de denúncia da violência doméstica e familiar contra mulher, assim como os de violência sexual. Os dados demonstram, de forma assustadora, o potencial avassalador que se configurou na relação de homens e mulheres na sociedade, que está atrelado a um histórico de submissão a outro gênero - que muitas das vezes é exercido por diferentes ângulos de violência.

\section{Considerações finais}

A intenção desse artigo foi evidenciar, através dos dados, diferentes formas de violência que os corpos das mulheres sofrem na sociedade brasileira. Os números demonstram a permanência de uma sociedade opressora, que enxerga no corpo da mulher um espaço público e violável. Ademais, demonstraram-se os avanços jurídicos a partir das categorizações aplicadas para entender as formas de violência sexual, além de identificar esse problema como uma questão de saúde pública.

A partir da pesquisa, notou-se que a subnotificação acaba por dificultar o conhecimento exato da dimensão do problema. Ainda assim, vale ressaltar que os registros existentes podem gerar um material amplo, cuja análise reforça o contexto problemático da situação.

A estratégia de destacar e visibilizar esse problema aumenta a possibilidade de incentivar e cobrar a criação de políticas públicas que minimizem e erradiquem a violência. Encontram-se diante de limites e desafios, mas romper com a violência é um processo que precisa de muitas mãos. Por isso, fortalecer as redes de apoio e proteção, e dar cada vez mais força para a criação de ambientes favoráveis ao empoderamento social, político e psicológico das vítimas, com vistas ao rompimento da situação de violência, é crucial.

É preciso pensar em novas práticas que auxiliem na prevenção da violência, em um trabalho de conscientização junto à população. Esse trabalho permitiria que, de forma gradativa, se tornassem capazes de enxergar toda essa violência que atinge diariamente à 
sociedade e não mais naturalizá-la, uma vez que isso gera a aceitação dessas situações como algo corriqueiro e banal.

Um dos caminhos é a educação básica, através da disputa por currículos escolares que contenham e evidenciem a questão da violência sexual contra a mulher - como um problema da sociedade brasileiro.

\section{Referências}

BARROS, Nivia Valença. Violência intrafamiliar contra criança e adolescente: Trajetória histórica, políticas sociais, práticas e proteção social. Rio de Janeiro: PUC-Rio, Departamento de Psicologia, 2005.

BOURDIEU, P. O poder simbólico. Rio de Janeiro: Bertrand Brasil S.A, 1989.

.A Dominação masculina. Rio de Janeiro: Bertrand Brasil S.A, 2002.

BRASIL. Ministério da Saúde. Violência faz mal à saúde. Brasília: Ministério da Saúde, 2004.

BRASIL. Presidência da República. Lei Maria da Penha. Lei N. ${ }^{\circ} 11.340$, de 7 de agosto de 2006.

CAMPOS, MayãPólo de, SILVA, Joseli Maria, SILVA, Edson Armando. Emoção corporificada e potência para constituição de espaços de luta para superar a violência sexual sofrida por mulheres. Caderno Prudentino de Geografia, Presidente Prudente, n. 41, v. 3, Dossiê "Geografias interseccionais: gênero, raça, corpos e sexualidades" p. 37-50, jul-dez, 2019. Disponível em:

<>.http://revista.fct.unesp.br/index.php/cpg/article/viewFile/6401/4993Acesso em: 20abr. de 2021.

CERQUEIRA, Anne Kellen C. et al. O Sofrimento da Mãe frente à violência doméstica e ao abuso sexual sofrido pelas suas filhas/os: aspectos socioeducacionais, psicológicos e jurídicos. SOUZA, Marisa Chaves de, SANTOS, Douglas Bianchi dos. Fortalecendo a rede de proteção à criança e ao adolescente: desafios e possibilidades para a equipe do NEACA de São Gonçalo - RJ/São Paulo: all Print Editora, 2015.

CHAUÍ, Marilena. Sobre a violência/ Marilena Chauí; organizadoras Ericka Marie itokazu, Luciana Chauí-Berlinck. - 1. Ed.; 2 reimp. - Belo horizonte: Autêntica editora, 2019. (Escritos de Marilena Chauí; v.5)

COELHO, Elza Berger Salema ET all (org). Violência: definições e tipologias [recurso eletrônico] / Universidade Federal de Santa Catarina; organizadores, - Florianópolis: Universidade Federal de Santa Catarina, 2014. 32 p.

DAVIS, Angela. Mulheres, Raça e Classe. São Paulo: Boitempo, 2016. . Mulheres, Cultura e Política. São Paulo: Boitempo, 2017. 
FEDERICI, Silvia. Calibã e a Bruxa: mulheres, corpo e acumulação primitiva/ Silvia Federici. Tradução ColetivoSycorax. São Paulo: Elefante, 2017.

. O ponto zero da revolução: trabalho doméstico, reprodução e luta feminista - São Paulo: Elefante, 2019.

FOUCAULT, Michel. Microfísica do poder. São Paulo: Graal, 1979. (O nascimento da medicina social. - pág. 46 a 56; O nascimento do hospital - pág. 99 a 111). (reimpressão, 2011).

. O sujeito e o poder. In: RABINOW, P. E DREYFUS, H. MICHEL . Uma trajetória filosófica. Para além do estruturalismo e da hermenêutica. Rio de Janeiro: Forense Universitária. 1995.

GONZALEZ, Lélia. Por um feminismo Afro-Latino-Americano. Caderno de formação política do Círculo. Palmarino No 1.2011.

A categoria político-cultural de amefricanidade. In: Tempo Brasileiro. Rio de Janeiro, No. 92/93 (jan./jun.). 1988b, p. 69-82.

hooks, bell, 1952 - O feminismo é para todo mundo: políticas arrebatadoras/ bell hooks; tradução Ana Luiza libânio - 4º ed. - Rio de Janeiro: Rosa dos tempos, 2019.

INSTITUTO DE SEGURANÇA PÚBLICA (Rio de Janeiro). MIRANDA, Ana Paula Mendes de; PINTO, Andréia Soares \& LAGE, Lana (Org.) Dossiê Mulher - Atualizado Arquivo disponível em: www.isp.rj.gov.br, Rio de Janeiro: ISP, 2006. Acesso em: 22 de abril de 2021.

INSTITUTO DE SEGURANÇA PÚBLICA (Rio de Janeiro). MIRANDA, Ana Paula Mendes de; PINTO, Andréia Soares \& LAGE, Lana. (Org.), Dossiê Mulher 2 Atualizado Arquivo disponível em www.isp.rj.gov.br, Rio de Janeiro: ISP, 2007. Acesso em: 22 de abril de 2021.

INSTITUTO DE SEGURANÇA PÚBLICA (Rio de Janeiro). DUARTE, Mário Sérgio de B. \& PINTO, Andréia Soares. (Org.). Dossiê Mulher. Arquivo disponível em www.isp.rj.gov.br, Rio de Janeiro: ISP, 2008. Acesso em: 22 de abril de 2021.

INSTITUTO DE SEGURANÇA PÚBLICA (Rio de Janeiro). Organizadores: Cel. PM Mário Sérgio de Brito Duarte Ten. Cel. PM Robson Rodrigues da Silva Andréia Soares Pinto.

Dossiê Mulher, Série Estudos/ Volume 2, 4. ed., Rio de Janeiro: [s. n.], 2009. Disponível em: <http://www.isp.rj.gov.br>. Acesso em: 22 abr 2021.

INSTITUTO DE SEGURANÇA PÚBLICA (Rio de Janeiro). Dossiê Mulher 2010 / Organizadores Paulo Augusto Souza Teixeira, Andréia Soares Pinto, Orlinda Cláudia R. Moraes - Rio de Janeiro: Riosegurança, 2010. 88p. Disponível em: <http://www.isp.rj.gov.br>. Acesso em: 22 abr. 2021.

INSTITUTO DE SEGURANÇA PÚBLICA (Rio de Janeiro). Dossiê mulher 2011. Organização Paulo Augusto Souza Teixeira Andréia Soares Pinto Orlinda Claudia R. Moraes. 
érie Estudos 2 - 6a Edição. Disponível em: 〈http://www.isp.rj.gov.br〉. Acesso em: 22 abr. 2021.

INSTITUTO DE SEGURANÇA PÚBLICA (Rio de Janeiro). Dossiê mulher 2012. Organização Paulo Augusto Souza Teixeira Andréia Soares Pinto Orlinda Claudia R. Moraes. Série Estudos 2 - $7^{a}$ Edição. Disponível em: 〈http://www.isp.rj.gov.br>. Acesso em: 22 abr. 2021.

INSTITUTO DE SEGURANÇA PÚBLICA (Rio de Janeiro). Dossiê Mulher 2013 / Instituto de Segurança Pública; Organizadores: Paulo Augusto Souza Teixeira, Andréia Soares Pinto e Orlinda Claudia R Moraes. - Rio de Janeiro: Riosegurança, 2013. Disponível em: <http://www.isp.rj.gov.br>. Acesso em: 22 abr. 2021.

INSTITUTO DE SEGURANÇA PÚBLICA (Rio de Janeiro). Dossiê Mulher 2014 / Instituto de Segurança Pública; Organizadores: Paulo Augusto Souza Teixeira e Andréia Soares Pinto. - Rio de Janeiro: Riosegurança, 2014. Disponível em: <http://www.isp.rj.gov.br>. Acesso em: 22 abr. 2021.

INSTITUTO DE SEGURANÇA PÚBLICA (Rio de Janeiro).). Dossiê mulher 2015. / Organizadores: Andréia Soares Pinto, Orlinda Cláudia R. de Moraes, Joana Monteiro. Disponível em: <http://www.isp.rj.gov.br>.Acesso em: 22 abr. 2021.

INSTITUTO DE SEGURANÇA PÚBLICA (Rio de Janeiro). Dossiê mulher 2016/ organizadores: Andréia Soares Pinto, Orlinda Claudia R. Moraes. - Rio de Janeiro : Instituto de Segurança Pública, 2016. Disponível em: 〈http://www.isp.rj.gov.br >. Acesso em: 22 abr. 2021.

INSTITUTO DE SEGURANÇA PÚBLICA (Rio de Janeiro). Dossiê mulher 2017/ Andréia Soares Pinto, Orlinda Cláudia R. de Moraes, Flávia Vastano Manso, organizadoras. - Rio de Janeiro: Instituto de Segurança Pública (ISP - RJ), 2017. Disponível em:

<http://www.isp.rj.gov.br>. Acesso em: 22 abr. 2021.

INSTITUTO DE SEGURANÇA PÚBLICA (Rio de Janeiro). Dossiê mulher 2018/ Orlinda Claudia R. de Moraes, Flávia Vastano Manso, organizadoras. - 13. versão. - Rio de Janeiro: RioSegurança. Instituto de Segurança Pública (ISP - RJ), 2018. Disponível em: <http://www.isp.rj.gov.br>. Acesso em: 22 abr. 2021.

INSTITUTO DE SEGURANÇA PÚBLICA (Rio de Janeiro). Dossiê mulher: 2019/orgs. Flávia Vastano Manso e Vanessa Campagnac. — 14. ed. — Rio de Janeiro :RioSegurança, 2019. Disponível em: 〈http://www.isp.rj.gov.br>. Acesso em: 22 abr. 2021

LOURO, Guacira Lopes. Um corpo estranho - ensaios sobre sexualidades e teoria queer/ Guacira Lopes Louro. - Belo Horizonte: Autêntica, 2004.

OLIVEIRA, Laís Paula Rodrigues de, Cassab. LatifAntonia. O movimento feminista: algumas considerações bibliográficas. Anais do III Simpósio Gênero e Políticas Públicas, ISSN 2177-8248 Universidade Estadual de Londrina, 27 a 29 de maio de 2014. Disponível em: 
<http://www.uel.br/eventos/gpp/pages/arquivos/GT10_La\%C3\%ADs\%20Paula\%20Rodrigue s\%20de\%20Oliveira\%20e\%20Latif\%20Cassab.pdf>.. Acesso: 20 abr. 2021.

SAFFIOTI, Heleieth. Gênero, patriarcado e violência. São Paulo: Editora Fundação Perseu Abramo, 2015.

SARTI, Cynthia Andersen. O feminismo brasileiro desde os anos 1970: revisitando uma trajetória. Estudos Feministas, Florianópolis, 12(2): 264, maio-agosto/2004.

SEPULVEDA, Denize. Emancipação social e exclusão no cotidiano escolar: a homofobia e sua influência nas tessituras identitárias. Tese (Doutorado em Educação). RJ, Universidade do Estado do Rio de Janeiro, 2012.

SILVA, Susana Veleda da. Os estudos de Gênero no Brasil: Algumas Considerações. Biblio 3W. Revista Bibliográfica de Geografía y CienciasSociales. Universidad de Barcelona, n. 262, nov. 2000. Disponível em: <http://repositorio.furg.br/bitstream/handle/1/1212/Os\%20estudos $\% 20 \mathrm{de} \% 20 \mathrm{~g} \% \mathrm{C} 3 \%$ AAnero $\% 20$ no\%20BRasil\%20algumas \%20considera\%C3\%A7\%C3\%B5es.pdf?sequence $=1>$.

Acesso em: 20 abr. 2021.

\footnotetext{
${ }^{i}$ A forte violência patriarcal agride também outros corpos como, por exemplo, mulheres e homens trans, homossexuais, bissexuais, lésbicas entre diversas e múltiplas sexualidades, identidades e gêneros.

ii A autora solicita que seu nome deve ser escrito de letra minúscula, na qual, tem o significado de chamar a atenção mais para o conteúdo de sua escrita do que ao seu nome.

iii Começa a partir da promulgação, em 2006, da Lei nº 4.785, que obriga o Estado a elaborar estatísticas sobre a violência contra mulher.

iv No site do ISP é possível acessar todos os dossiês em formato $p d f$, incluindo uma consulta interativa que disponibiliza dados desde 2014. Nesse formato de consulta, é possível buscar dados mais específicos de áreas do Estado do Rio de Janeiro.

v Os dossiês usam as denúncias que são feitas nas delegacias do Estado. Não utilizam apenas de denúncias feitas na Delegacia Especializada em Atendimento à Mulher - DEAM, mas em todas as delegacias do Estado do Rio de Janeiro. Como metodologia organiza, analisa e sintetizam dados da Polícia Civil, auxiliam na reflexão sobre a violência e na elaboração de políticas públicas. Leva em consideração o número de vítimas e não apenas de ocorrências, já que em uma denúncia pode haver mais de uma vítima. No decorrer dos documentos foi constatado que a maioria das delegacias que recebem atendimento são as delegacias comuns, no sentido geral, mas que as DEAM estão sempre no topo de denúncias de violência contra mulher em todo o estado.

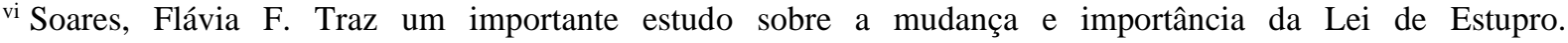
https://repositorio.uniceub.br/jspui/bitstream/123456789/364/3/20700763.pdf

vii Percebe-se, com esses dados, a importância da ampliação do debate sobre educação sexual nas escolas, tendo em vista que existe um público que sofre essa violência, assim como as outras, que estão presentes nesses espaços.
} 